\title{
Classe ideologia e política: uma interpretação dos resultados das eleições de 2002 e 2006
}

\author{
Denilde Oliveira Holzhacker \\ Bentley College - Cronin International Center \\ Elizabeth Balbachevsky \\ Universidade de São Paulo
}

\section{Resumo}

O artigo analisa os impactos da estratificação social e da identidade ideológica sobre o voto no Brasil nas eleições presidenciais de 2002 e 2006 e identifica os valores e atitudes associados ao voto em Lula nos dois pleitos. A análise baseada nos resultados do ESEB mostra o comportamento independente das duas variáveis explicativas do voto para presidente: em 2002, a estratificação social foi pouco relevante para explicar a decisão eleitoral, sobretudo o voto em Lula, que esteve significativamente associado com a auto-identidade ideológica. Em 2006, as variáveis impactam o voto para presidente de modo inverso. Não obstante essas diferenças, nos dois momentos, o voto em Lula em específico é mais fortemente explicado pela simpatia e identidade com o candidato.

Palavras-chave: eleição presidencial de 2006; estratificação social; identidade ideológica; classe média

Abstract

The article analyses the impact of social stratification and ideological identification on voting behavior in the Brazilian Presidential elections of 2002 and 2006, and, specifically, it identifies the values and attitudes associated with the vote for Lula. The analysis is based on the 2 waves of the ESEB (Brazilian Electoral Study) and it shows that in 2002, the social stratification was not a relevant factor in the explanation of presidential voting, especially the vote for Lula, associated with the self-ideological identification of citizens; in 2006, the situation is the opposite. However, in the 2 presidential campaigns, the vote for Lula is strongly explained by the voter's identification with the candidate.

Key-words: 2006 Presidential election; social stratification; ideological identity; middle class 
A divulgação dos resultados do primeiro turno da eleição presidencial de 2006 deu origem a diversas conjecturas acerca da decisão eleitoral de distintos grupos sociais da sociedade brasileira. Ainda durante a campanha, os analistas apontavam a existência de uma polarização econômica, social e regional inédita na história do país (SINGER, 2006). Os resultados oficiais por estados no primeiro turno reforçaram a percepção de uma polarização regional que, supostamente, se refletiu no interior de cada região, confrontando segmentos populares, de um lado, e as camadas médias da sociedade brasileira de outro. De fato, a geografia eleitoral das eleições de 2006 mostrou uma esmagadora vitória de Luiz Inácio Lula da Silva (PT/PRB/PC do B) entre os eleitores dos estados do norte e nordeste, enquanto os eleitores dos estados do sul e sudeste escolheram, em sua maioria, Geraldo Alckmin (PSDB/PFL). Algumas análises sugeriam que a explicação para uma possível divisão do país entre norte/nordeste, de um lado, e sul/sudeste, de outro lado, era bastante simplista. De fato, as pesquisas de opinião realizadas durante a campanha mostravam que o candidato Lula vencia as eleições entre os eleitores de baixa renda no sul/sudeste, ao passo que Alckmin tinha maior apoio entre os eleitores de renda média-alta nos estados do norte/nordeste (FUNDAÇÃO PERSEU ABRAMO, 2006).

As interpretações desse resultado variaram bastante. Para alguns analistas, os mais pobres se inclinariam a favor do candidato ex-operário que, no seu primeiro mandato, tinha tido sucesso na implementação de políticas compensatórias visando corrigir as desigualdades históricas. No outro extremo, estaria uma elite insensível às desigualdades que marcam a sociedade brasileira e refratária às demandas populares (SINGER, 2006). Na decisão de voto desta elite pesava também uma grande dose de preconceito contra o presidente-operário e sua política. Outros analistas, mais céticos, explicaram a escolha eleitoral em função de diferentes graus de sofisticação da informação entre eleitores de distintos estratos sociais. Nessa abordagem, o desempenho eleitoral de Lula, passado menos de um ano dos incidentes que ligavam seu governo a um esquema de desvio de recursos públicos para a compra de apoio político no Congresso, poderia ser entendido em função da maior ou menor sofisticação de diferentes setores do eleitorado. Segundo essa interpretação, os grupos mais pobres e com menor escolaridade seriam desprovidos de instrumentos cognitivos necessários para decidir o seu voto a partir de uma interpretação mais ampla do cenário político. Esses setores seriam mais suscetíveis à manipulação da informação feita pelo governo, e também mais vulneráveis às estratégias de clientela que muitas vezes acompanham políticas de perfil assistencialista. De outro lado, eleitores pertencentes aos estratos médio e alto seriam menos vulneráveis ao jogo de manipulação de informações feito pelo governo e, conseqüentemente, tenderiam a ser mais críticos com relação à avaliação geral do governo, já que trabalhavam com a memória da conjuntura do 
BALBACHEVSKY, E.; HOLZHACKER, D. O. Classe, ideologia e política: uma interpretação...

ano anterior. Em algumas interpretações, esses setores teriam também uma avaliação mais crítica sobre o desempenho do governo com relação à implementação da agenda de reformas capazes de sustentar o desenvolvimento do país (BRESSER-PEREIRA, 2006).

O ponto comum a todas essas interpretações é o destaque dado à decisão de voto da classe média em contraposição a dos setores populares. Por outro lado, é consenso na literatura nacional o reconhecimento de que a classe média teve papel de destaque em diferentes momentos da história eleitoral do país (BRESSERPEREIRA, 2006; OWENSBY, 1999). Entretanto, entre os estudos sobre as recentes eleições no Brasil, não é possível localizar análises específicas que considerem a estratificação social e seu impacto sobre a decisão de voto. Apesar da variável socioeconômica ser explorada em alguns estudos (SINGER, 2002; CARREIRÃOCARREIRÃO, 2007; NICOLAU, 2007), esta costuma aparecer como uma abordagem menor, ao lado de outras variáveis demográficas e de comportamento político. Este artigo busca cobrir tal lacuna, analisando os determinantes sociais do voto nas eleições de 2002 e 2006, em contraposição com o seu perfil ideológico e programático. Os resultados de nossas análises mostram um padrão bastante singular de evolução da decisão do voto entre essas duas eleições: por um lado, confirmam a percepção geral de que o voto em Lula tendeu a crescer e, ao mesmo tempo, se concentrar junto aos eleitores das chamadas camadas populares; por outro lado, o significado deste voto perdeu nitidez do ponto de vista ideológico, mostrando-se muito mais associado a uma identidade difusa com o candidato do que com uma percepção que comporte a elaboração de cenários mais sofisticados da política nas eleições de 2006.

O número restrito de estudos sobre o impacto da estratificação social no comportamento eleitoral muito provavelmente está relacionado à dificuldade de operacionalização deste conceito. A questão central aqui está em estabelecer quais variáveis deveriam ser incorporadas para gerar um retrato fiel da composição da sociedade brasileira. Para responder a essa pergunta, na primeira parte do artigo analisamos as diferentes definições na literatura sobre classes e estratificação social, dando especial ênfase para a definição dos estratos médios. Em seguida, a partir da análise dos dados do survey ESEB, buscamos criar alguns indicadores que permitem estratificar os entrevistados de nossa amostra e analisar alguns dos vetores que compõem a decisão dos eleitores dos estratos médios, quando comparados com outros setores da sociedade brasileira. Com efeito, um dos atributos centrais dos estratos intermediários é sua heterogeneidade (GERTEIS, 1998). A parcela da população incluída dentro da classe média constitui justamente o grupo de maior variância interna, qualquer que seja o indicador tomado como referência. Dentro desse estrato social estão categorias tão díspares como, por exemplo, motoristas de táxi e professores universitários. Assim, estabelecer 
parâmetros aceitáveis para identificar os diferentes estratos da sociedade brasileira é o primeiro desafio deste estudo. Em seguida, a partir da análise dos dados do ESEB, buscamos criar alguns indicadores que permitem estratificar os entrevistados das amostras relativas às eleições de 2002 e 2006 e analisar alguns dos vetores que compuseram a decisão dos eleitores pertencentes a diferentes estratos sociais nessas duas eleições.

\section{Estratos sociais e renda no Brasil}

O'Dougherty (2002), em seu estudo sobre o comportamento, atitudes e identidade da classe média brasileira, descreve sua surpresa relacionada com a dificuldade para identificar e classificar a classe média brasileira, em contraposição a outros estratos da sociedade. A propósito, em seu exame da literatura, o autor notou que essa não era uma constatação exclusiva do seu estudo. Grande parte do debate, na literatura brasileira, sobre estratificação social está centrado na classificação das matrizes e diferenças encontradas no interior da classe média e, ao mesmo tempo, no estabelecimento de fronteiras nítidas entre tal setor e os demais estratos da sociedade brasileira.

Essa é uma dificuldade geral que a literatura internacional enfrenta quando analisa processos de estratificação social. Uma questão central nessas discussões é a escolha de parâmetros que definam os limites de pertinência de cada estrato (GERTEIS, 1998). De maneira geral, os critérios mais utilizados para definir esses diferentes segmentos são os rendimentos auferidos e a posição ocupacional obtida no interior do mercado de trabalho (GUERRA et al, 2006).

$\mathrm{Na}$ literatura internacional, a emergência e a força desses setores médios estão associadas ao desenvolvimento do capitalismo e à formação de estruturas sociais complexas, cuja realidade aponta para as insuficiências dos modelos clássicos derivados da teoria marxista, que separam os grupos sociais exclusivamente em função da propriedade dos meios de produção. A definição tradicional de classe média é de Mills (1956), que analisa a classe média norteamericana a partir de um esquema baseado na posição ocupacional. Para esse autor, classe média corresponde ao grupo dos empregados não manuais, por ele denominado de white collars. De acordo com Mills, os grupos da nova classe média são, estruturalmente, diferentes dos capitalistas e da "antiga classe média", composta por pequenos comerciantes, artesãos e pequenos proprietários em geral. A nova classe média seria composta de empregados que ocupam estruturalmente uma posição semelhante àquela ocupada pelos trabalhadores assalariados. Por esse motivo, a distinção entre a classe trabalhadora e a nova classe média é mais sutil. Em ambos os casos, trata-se de uma relação de trabalho 
BALBACHEVSKY, E.; HOLZHACKER, D. O. Classe, ideologia e política: uma interpretação...

assalariada. Entretanto, tipicamente, a classe média tem empregos ligados ao trabalho não manual, enquanto a classe trabalhadora estaria ligada às ocupações manuais. Gerteis (1998) argumenta que o conceito de ocupação é relevante para a distinção de diferentes estratos sociais e, em especial, dos setores médios, por ser uma maneira simples e relativamente direta de identificar diferentes posições de status.

Os estudos feitos no Brasil incorporam a questão ocupacional, mas, agregam a ela o conceito de status, que é avaliado pelas categorias de consumo, renda e escolaridade. É consenso na literatura brasileira que a complexidade da estrutura social brasileira é resultado do modelo de desenvolvimento nacional a partir dos anos trinta. Os processos de urbanização do país e o desenvolvimento industrial, como também a expansão das atividades do Estado e a constituição de uma burocracia nacional foram fatores importantes para a ampliação do peso dos setores médios na vida nacional ${ }^{1}$ (GUERRA et al, 2006; BRESSER-PEREIRA, 1962; OSWENSBY, 1999). Segundo um estudo recente realizado na Unicamp, a classe média brasileira representaria hoje cerca de $31 \%$ da população brasileira (GUERRA et al, 2006). Ademais, esses processos também foram responsáveis pelo crescimento dos estratos populares urbanos e pela diminuição relativa do peso da população rural em nossa sociedade, em especial do trabalhador rural.

A questão dos indicadores de status é central no debate sobre a delimitação das fronteiras de classe. Guerra et al afirmam que é importante reconhecer que os segmentos médios se caracterizam "por posições intermediárias tanto na estrutura sócio-ocupacional como na distribuição de renda" e, conseqüentemente, são "portadora(s) de autoridade e status social reconhecido e avantajado padrão de consumo" (GUERRA et al, 2006, p.16). Owensby (1999) dá ênfase ao critério da educação formal (o diploma universitário servindo com o delimitador da classe média). Santos (2005), por sua vez, propõe uma nova classificação econômica. A partir do conceito de classe social, o autor propõe uma estratificação que permita a descrição e explicação dos mecanismos de produção e reprodução das desigualdades no interior da sociedade brasileira. Outros autores incorporam também variáveis relativas ao padrão de consumo. De acordo com O'Dougherty (2002), a sustentação do modo de vida está diretamente associada à formação de identidade dos grupos médios². Incorporando essa perspectiva, Guerra et al (2006) sustentam que tal fator é fundamental no caso brasileiro, pois a preservação do padrão de consumo da classe média viu-se afetada pelas crises econômicas dos

\footnotetext{
${ }^{1}$ Hasenbalg e Silva (1988), analisando a mobilidade social no Brasil entre os anos 40 e 80, concluíram que entre as décadas de 60 e 80 surgiu uma nova classe média urbana, resultado de 5,7 milhões de empregos não-manuais de rotina criados pela expansão da economia urbana nesse período.

2 Este fator, como demonstrado por O’Dougherty (2002), é essencial para compreender a gênese da classe média no mundo, inclusive no Brasil. Outro fator importante sobre os segmentos médios no Brasil é que estudos, relacionados ao consumo, mostram que houve fortes mudanças nestes estratos no Brasil após a abertura comercial e a democratização.
} 
anos 80 e início dos anos 90. Todavia, para esses autores, os padrões de consumo relacionam-se diretamente com a posição ocupacional e, conseqüentemente, com o nível de rendimento.

Do ponto de vista empírico, os critérios mais utilizados são a renda familiar e a renda familiar per-capita, dada sua maior simplicidade. Quadros (2006), por exemplo, adotou linhas de cortes fixas ${ }^{3}$ para os rendimentos médios individuais e fixou seus valores (em janeiro de 2004) em múltiplos de $R \$ 250$, valor um pouco acima do salário mínimo vigente na época, de $R \$ 240,00$. Com base nessa análise, o autor identificou a seguinte estrutura de renda:

\begin{tabular}{|c|c|}
\hline $\begin{array}{c}\text { Faixas de rendimentos individuais } \\
\text { médios }\left(^{*}\right)\end{array}$ & "Padrões de vida" \\
\hline Acima de $\mathrm{R} \$ 2.500$ & Alta classe média \\
\hline $\mathrm{R} \$ 1.250$ a $\mathrm{R} \$ 2.500$ & Média classe média \\
\hline $\mathrm{R} \$ 500$ a $\mathrm{R} \$ 1.250$ & Baixa classe média \\
\hline $\mathrm{R} \$ 250$ a $\mathrm{R} \$ 500$ & Massa trabalhadora \\
\hline Abaixo de $\mathrm{R} \$ 250$ & Miseráveis \\
\hline
\end{tabular}

Fonte: Quadros (2006, p.5).

A partir desse critério, Quadros propõe uma análise da distribuição dos estratos sociais brasileiros e do impacto do Plano Real para a estratificação da sociedade brasileira. Sua conclusão é que o Plano Real representou uma recuperação na renda de todas as classes sociais. Os miseráveis, que antes representavam $48,2 \%$ da população, passaram a representar $38 \%$ em 1995, caindo para 35,9\% em 1996. Já as classes médias apresentaram um crescimento expressivo: a alta classe média representava 4,1\% em 1993 e passou para 7,3\% em 1996; a média classe média, de $6,7 \%$ passou para $10 \%$ no mesmo período; a baixa classe média, por fim, representava $19 \%$ e passou para 25,2\%. Esses dados indicam o efeito positivo do Plano Real para todos os estratos da sociedade.

${ }^{3} \mathrm{O}$ autor argumenta que na sua classificação não se encontram os ricos, pois estes, em geral, não são entrevistados nas pesquisas do IBGE, e quando são, tendem a adotar uma posição para mascarar a renda de forma a pertencer a alta classe média. Por isso, a análise deste grupo deve ser feita a partir de outros critérios e outras fontes de informação. 
BALBACHEVSKY, E.; HOLZHACKER, D. O. Classe, ideologia e política: uma interpretação...

Quadro 1 - Distribuição dos Estratos Sociais · Brasil

\begin{tabular}{|c|c|c|c|c|c|c|}
\cline { 2 - 6 } \multicolumn{1}{c|}{} & \multicolumn{5}{c|}{ Padrões de Vida } & \multirow{2}{*}{} \\
\hline Anos & $\begin{array}{c}\text { Alta Classe } \\
\text { Média }\end{array}$ & $\begin{array}{c}\text { Média Classe } \\
\text { Média }\end{array}$ & $\begin{array}{c}\text { Baixa Classe } \\
\text { Média }\end{array}$ & $\begin{array}{c}\text { Massa } \\
\text { Trabalhadora }\end{array}$ & Miseráveis & Total \\
\hline 1990 & 5,3 & 8,2 & 22,0 & 19,8 & 44,6 & $100 \%$ \\
\hline 1992 & 3,6 & 7,2 & 20,0 & 23,6 & 45,6 & $100 \%$ \\
\hline 1993 & 4,1 & 6,7 & 19,0 & 22,0 & 48,2 & $100 \%$ \\
\hline 1995 & 5,9 & 8,6 & 22,6 & 24,9 & 38,0 & $100 \%$ \\
\hline 1996 & 7,3 & 10,1 & 25,2 & 21,5 & 35,9 & $100 \%$ \\
\hline 1997 & 5,6 & 9,6 & 22,4 & 23,0 & 39,4 & $100 \%$ \\
\hline 1998 & 5,7 & 9,8 & 22,8 & 23,4 & 38,2 & $100 \%$ \\
\hline 1999 & 5,3 & 8,2 & 24,0 & 24,1 & 38,4 & $100 \%$ \\
\hline 2001 & 5,4 & 8,5 & 23,7 & 26,1 & 36,3 & $100 \%$ \\
\hline 2002 & 4,7 & 7,8 & 22,6 & 26,5 & 38,5 & $100 \%$ \\
\hline 2003 & 4,5 & 6,8 & 23,5 & 25,9 & 39,3 & $100 \%$ \\
\hline 2004 & 4,1 & 7,3 & 22,2 & 28,4 & 38,0 & $100 \%$ \\
\hline 2005 & 4,6 & 7,9 & 25,6 & 40,1 & 21,7 & $100 \%$ \\
\hline
\end{tabular}

Fonte: Quadros (2006, p.8.9)

No entanto, durante o restante da década de 90 , que foi marcada por diversas crises econômicas e financeiras, culminando na desvalorização do Real, em 1999, percebe-se que a proporção dos grupos ligados à classe média, principalmente à alta e à média, diminui, voltando para os patamares próximos aos observados em 1993. Assim, em 2005, apenas 4,6\% da população poderiam ser classificados como alta classe média e só 7,9\% como média classe média. 0 estrato de baixa classe média, entretanto, preserva a posição alcançada após o Plano Real, representando $25 \%$ da população total.

Uma conclusão desse estudo aponta o forte crescimento do estrato de renda denominado classe trabalhadora. Esse grupo representava 22\% em 1993, e passou a representar 40,1\% em 2005. No sentido oposto, o grupo dos miseráveis, com rendimentos abaixo de $\mathrm{R} \$ 250,00$ passou de um patamar de 48\% em 1993 para $21,7 \%$ em 2005. É bastante provável que este grupo foi um dos maiores beneficiados pelos programas de transferências de renda, introduzidos primeiro na administração de Fernando Henrique e, posteriormente, expandidos na de Luiz Inácio Lula da Silva ${ }^{4}$.

\footnotetext{
${ }^{4}$ Quadros argumenta que este fato ocorre primeiro por que o corte de renda está abaixo do valor do salário mínimo em 2005. Em segundo lugar, os programas focalizados de transferência de renda fizeram com que este grupo fosse transferido para o grupo acima.
} 
A análise da evolução de cada um dos estratos de rendimentos médios no Brasil é relevante, pois grande parte dos argumentos sobre o posicionamento eleitoral destes grupos está centrado na suposição de que tais segmentos foram afetados pela estagnação econômica e disso decorre seu apoio ou não à determinada administração. Os dados agregados apresentados por Quadros (2006) corroboram a hipótese de que a inclinação oposicionista entre eleitores da classe média pode estar associada a uma insatisfação com a falta de ganhos econômicos nas últimas décadas. Os estratos mais pobres, beneficiados pelas políticas de transferência de renda, têm maiores motivos para uma avaliação mais benevolente da ação governamental.

Figueiredo (2004), entretanto, faz uma crítica ao uso do indicador de renda como única referência para identificação dos estratos sociais, sugerindo que essa classificação incorpore algum critério de status. Deste modo, outro critério utilizado nas pesquisas de opinião para identificar os estratos são as faixas de consumo. Desde os anos 70, as pesquisas de opinião e consumo no Brasil adotaram os critérios de padronização socioeconômica da população brasileira tendo por base diferentes padrões de consumo. O critério desenvolvido pela Associação Brasileira de Institutos de Pesquisa de Mercado tem como objetivo dividir a população em categorias de status segundo padrões ou potenciais de consumo. Dessa forma, por intermédio da atribuição de pesos a um conjunto de itens de conforto doméstico e também do nível de escolaridade do chefe de família, cria-se uma escala socioeconômica que divide a população em cinco "classes", ou melhor, padrões socioeconômicos: A1, A2, B1, B2, C, D, E.

O critério de classificação socioeconômica é bastante usual no Brasil, pois oferece uma medida considerada mais exata das diferenças de renda. Isto porque, em geral, numa situação de entrevista, a literatura aponta uma tendência de os entrevistados ou omitirem ou subvalorizarem a renda familiar e pessoal. Dessa forma, as faixas de consumo serviriam como um controlador do critério renda. Todavia, mesmo após diversos estudos sobre a aplicabilidade do conceito e sua precisão, as críticas com relação à classificação ainda persistem. A principal crítica é que a classificação não leva em conta o fator educacional.

Portanto, podemos concluir que todos os critérios adotados visando estratificar a sociedade brasileira apresentam limitações metodológicas. Por outro lado, os estudos realizados sobre a realidade brasileira mostram que o indicador renda é uma variável fortemente correlacionada a todas as demais variáveis descritas acima. A correlação entre os indicadores socioeconômicos e a renda, por exemplo, nas análises feitas por ocasião da construção da escala, foi de 0,72\% e era significativa a mais de 99,9\% (MATTAR, 1995). 
BALBACHEVSKY, E.; HOLZHACKER, D. O. Classe, ideologia e política: uma interpretação...

Por esse motivo, neste artigo, optou-se pela definição de Quadros (2006) que considera as divisões intermediárias de renda ${ }^{5}$ : média-baixa, média-média e média-alta. Consideramos que a subdivisão entre os estratos poderia contribuir para uma análise mais acurada do comportamento dos grupos intermediários. As razões para essa decisão estão discutidas abaixo. Entretanto, é possível adiantar que, no banco de dados da pesquisa ESEB, constatamos uma associação entre as faixas de renda e os critérios de educação e de estratificação socioeconômica bastante similares aos padrões indicados na literatura (GUERRA et al, 2006). Por outro lado, os dados disponíveis no banco de dados gerado pela pesquisa não permitem a análise a partir do critério de posição ocupacional ${ }^{6}$.

Os resultados da pesquisa em 2006 mostram que, aproximadamente, 40\% ${ }^{7}$ dos entrevistados podem ser classificados nas faixas de renda média-baixa $(25,5 \%)$, média-média $(14,9 \%)$ e média-alta $(5,1 \%)$.

Quadro 2 - Estratificação da renda dos entrevistados (\%)

\begin{tabular}{|c|c|c|}
\hline $\begin{array}{c}\text { Estratificação por renda } \\
\text { média }\end{array}$ & $\begin{array}{c}\text { Total de } \\
\text { casos }\end{array}$ & porcentagem \\
\hline Baixa renda & 487 & 54,0 \\
\hline Média Baixa & 230 & 25,5 \\
\hline Média média & 134 & 14,9 \\
\hline Média Alta & 51 & 5,7 \\
\hline Total & 902 & 100,0 \\
\hline
\end{tabular}

Fonte: ESEB, 2006.

Os dados da Tabela 1 mostram que o grupo de renda média-alta localiza-se majoritariamente nos estratos A/B1 e B2 da população, representando $43 \%$ dos entrevistados nessa categoria. Já os eleitores de renda média-média se subdividem entre os estratos B2 e C, que representam 25\% e 52\%, respectivamente. Por sua vez, os entrevistados de renda média-baixa concentram-se no estrato $C(54 \%)$ e os eleitores de renda baixa nos estratos D/E (65,5\%). Um padrão semelhante pode ser

\footnotetext{
${ }^{5}$ Os grupos definidos por Quadros (2006) como miseráveis e classe trabalhadora foram agrupados e considerados como "renda baixa".

6 Os entrevistados foram apenas identificados como trabalhadores assalariados, não assalariados (autônomos), pensionistas/aposentados, donas de casa e estudantes. A partir dos critérios da população economicamente ativa, no entanto, não foram questionados por ocupação.

${ }^{7}$ No estudo de Guerra et al (2006), o percentual de famílias pertencentes à classe média é de 31\%, o que representaria 15,4 milhões de famílias. Convertendo ao número de pessoas os autores consideram 57,8 milhões de brasileiros pertencentes à classe média brasileira, com uma renda per capita entre $R \$$ 263,00 (1,7 salários mínimos) e R\$2.928,00 (19 salários mínimos) (GUERRA et al, op.cit., p.64).
} 
verificado quando se analisam, especificamente, as informações sobre a posse de e acesso a alguns itens de consumo típicos da classe média, como computador e TV a cabo.

Quando se considera o nível de escolaridade dos entrevistados, educação superior está associada aos grupos de renda média-média e média-alta. Por outro lado, educação média está fortemente associada à classe média, ou seja, os entrevistados classificados nessa faixa tipicamente cursaram o ensino médio (completo ou incompleto). Já a baixa escolaridade está associada à população de baixa renda.

Tabela 1 - Escolaridade, Classe Social e Posse de computador e TV a cabo de acordo com a estratificação da renda familiar (\%)

\begin{tabular}{|c|c|c|c|c|c|}
\hline & \multicolumn{4}{|c|}{ Estratificação de Renda } & \multirow[b]{2}{*}{ Total } \\
\hline & Baixa renda & Média Baixa & Média média & Média alta & \\
\hline \multicolumn{6}{|l|}{ Socioeconômico } \\
\hline \multirow[t]{2}{*}{ A/B1 } & 0 & 2,2 & 9,7 & 43,1 & 4,4 \\
\hline & $\cdot 7,0$ & $.1,9$ & 3,2 & 13,8 & \\
\hline \multirow[t]{2}{*}{ B2 } & 8 & 12,2 & 25,4 & 33,3 & 9,2 \\
\hline & $.9,4$ & 1,8 & 7,0 & 6,1 & \\
\hline \multirow[t]{2}{*}{ C } & 33,7 & 54,8 & 52,2 & 23,5 & 41,2 \\
\hline & $.5,0$ & 4,8 & 2,8 & $\cdot 2,6$ & \\
\hline \multirow[t]{2}{*}{$\mathrm{D} / \mathrm{E}$} & 65,5 & 30,9 & 12,7 & 0 & 45,1 \\
\hline & 13,3 & $.5,0$ & 8,2 & $\cdot 6,7$ & \\
\hline Total $(100 \%)$ & $(487)$ & (230) & $(134)$ & $(51)$ & $(902)$ \\
\hline \multicolumn{6}{|l|}{ Escolaridade } \\
\hline \multirow[t]{2}{*}{0 a 4 anos } & 48,5 & 28,3 & 18,7 & 3,9 & 36,4 \\
\hline & 8,2 & $.3,0$ & $.4,6$ & $.5,0$ & \\
\hline \multirow[t]{2}{*}{5 a 8 anos } & 28,1 & 27,4 & 23,9 & 15,7 & 26,6 \\
\hline & 1,1 & ,3 & $\cdot, 8$ & $\cdot 1,8$ & \\
\hline \multirow[t]{2}{*}{9 a 11 anos } & 21,1 & 35,7 & 33,6 & 37,3 & 27,6 \\
\hline & 4,7 & 3,2 & 1,7 & 1,6 & \\
\hline \multirow[t]{2}{*}{ Superior } & 2,3 & 8,7 & 23,9 & 43,1 & 9,4 \\
\hline & 8,0 & $\cdot, 4$ & 6,2 & 8,5 & \\
\hline Total & $(487)$ & $(230)$ & $(134)$ & $(51)$ & $(902)$ \\
\hline
\end{tabular}


BALBACHEVSKY, E.; HOLZHACKER, D. O. Classe, ideologia e política: uma interpretação...

\begin{tabular}{|c|c|c|c|c|c|}
\hline & \multicolumn{4}{|c|}{ Estratificação de Renda } & \multirow[b]{2}{*}{ Total } \\
\hline & Baixa renda & Média Baixa & Média média & Média alta & \\
\hline \multicolumn{6}{|c|}{ Computador } \\
\hline \multirow[t]{2}{*}{ Sim } & 4,1 & 17,4 & 32,1 & 70,6 & 15,4 \\
\hline & $\cdot 10,2$ & 1,0 & 5,8 & 11,2 & \\
\hline \multirow[t]{2}{*}{ Não } & 95,9 & 82,6 & 67,9 & 29,4 & 84,6 \\
\hline & 10,2 & $\cdot 1,0$ & $.5,8$ & $.11,2$ & \\
\hline Total & $(487)$ & $(230)$ & $(134)$ & $(51)$ & $(902)$ \\
\hline \multicolumn{6}{|c|}{ TV a cabo } \\
\hline \multirow[t]{2}{*}{ Sim } & 3,1 & 14,8 & 26,1 & 43,1 & 11,8 \\
\hline & $\cdot 8,8$ & 1,7 & 5,6 & 7,2 & \\
\hline \multirow[t]{2}{*}{ Não } & 96,9 & 85,2 & 73,9 & 56,9 & 88,2 \\
\hline & 8,8 & $\cdot 1,7$ & $.5,6$ & $\cdot 7,2$ & \\
\hline Total & $(487)$ & $(230)$ & $(134)$ & $(51)$ & $(902)$ \\
\hline
\end{tabular}

\begin{tabular}{|c|c|c|c|}
\hline Chi quadrado (pearson) & Valor & Grau de Liberdade & Significância \\
\hline Estrato Socioeconômico & $448,867(\mathrm{a})$ & 9 &, 000 \\
\hline Escolaridade & $187,296(\mathrm{~b})$ & 9 &, 000 \\
\hline Possui Computador & $196,142(\mathrm{c})$ & 3 &, 000 \\
\hline Possui TV a Cabo & $112,465(\mathrm{~d})$ & 3 &, 000 \\
\hline
\end{tabular}

Fonte: ESEB, 2006.

A alta correlação entre as variáveis de estratificação da renda, escolaridade e estrato socioeconômico torna as tentativas de unificar essas variáveis em uma variável composta para a identificação dos estratos sociais pouco operacionais. Os testes mostraram que a combinação desses indicadores torna os grupos intermediários mais dispersos. Por outro lado, como vimos, os resultados da análise bivariada mostram que a variável renda apresenta forte correlação com todas as demais variáveis e, portanto, pode ser aceita como indicador satisfatório do pertencimento do entrevistado a um dos diferentes estratos da sociedade brasileira. Por esse motivo, optou-se por conduzir a análise considerando a estratificação de renda familiar per capita como o fator delimitador dos estratos sociais. 


\section{Classe social e voto nas eleições de 2002 e 2006}

A Tabela 2 apresenta a decisão de voto em primeiro turno por estrato social nas eleições de 2002 e 2006. Como é possível observar nesta tabela, voto e estrato social estiveram significativamente associados tanto nas eleições de 2002 como nas eleições de 2006. A associação entre essas duas variáveis, para cada uma das eleições, pode ser evidenciada mediante a análise dos resíduos ajustados ${ }^{8}$ que estão subscritos em cada célula. É possível verificar que, na eleição de 2002, existe uma associação significativa e positiva entre, de um lado, o voto em Serra e Ciro Gomes e o estrato mais alto da amostra (renda média-alta). Ao contrário, quando se analisa o padrão de votação em Lula, o voto nesse candidato, em 2002, não estava especialmente associado com nenhum estrato social. Considerando os eleitores de cada estrato separadamente, vemos que a proporção de eleitores que declarou seu voto em Lula não varia significativamente, com exceção, mais uma vez, dos eleitores do estrato mais alto. Entre esses eleitores constata-se uma pequena, porém significativa, queda na preferência pela candidatura de Lula, que varia de $53 \%$ na população em geral, para $47 \%$ entre os eleitores da classe média-alta.

\footnotetext{
8 Os resíduos ajustados são utilizados para a análise do padrão de inter-relacionamento entre duas variáveis, captados pela estatística $\mathrm{F}^{2}$. Por esse procedimento, calcula-se inicialmente o resíduo padronizado de cada célula, dado por eij $=\left(n_{\mathrm{ij}} \cdot \mathrm{e}_{\mathrm{ij}}\right) / \square \mathrm{e}_{\mathrm{ij}}$, no qual $\mathrm{e}_{\mathrm{ij}}$ é o total de casos esperado na célula, sendo verdadeira a hipótese nula. Em seguida ajusta-se esse resíduo pela variância estimada da célula $\left(v_{i j}=\left(1-N_{i} . / N ..\right)(N . j / N .\right.$.$) . Portanto, o resíduo ajustado é dado por d_{i j}=e_{i j} / \square v_{i j}$

Quando as variáveis em uma tabela são independentes, os resíduos ajustados têm uma distribuição normal, o que significa que eles permanecem dentro do intervalo de $\pm 1,96$, para $D=0,05$. Portanto, as células cujo resíduo ajustado é maior, em valor absoluto, que 1,96 têm um número de casos significativamente diferentes do esperado pela hipótese nula.
} 
BALBACHEVSKY, E.; HOLZHACKER, D. O. Classe, ideologia e política: uma interpretação...

Tabela 2 - Escolha eleitoral nas eleições de 2002 e 2006

de acordo com a estratificação social

\begin{tabular}{|c|c|c|c|c|c|}
\hline \multirow[b]{2}{*}{$\begin{array}{l}\text { Escolha eleitoral } \\
\text { 1o. Turno } 2002\end{array}$} & \multicolumn{4}{|c|}{ Estratificação Social } & \multirow[b]{2}{*}{ Total } \\
\hline & Classe Baixa & Média-Baixa & Média-Média & Média-Alta & \\
\hline Lula & $\begin{array}{c}52,9 \% \\
\cdot, 1 \\
\end{array}$ & $\begin{array}{c}58,9 \% \\
2,7 \\
\end{array}$ & $\begin{array}{c}57,0 \% \\
1,2 \\
\end{array}$ & $\begin{array}{c}46,9 \% \\
.3,3 \\
\end{array}$ & $53,1 \%$ \\
\hline Ciro & $\begin{array}{c}9,3 \% \\
\cdot, 6 \\
\end{array}$ & $\begin{array}{c}5,9 \% \\
-3,0 \\
\end{array}$ & $\begin{array}{c}12,2 \% \\
1,3\end{array}$ & $\begin{array}{c}12,6 \% \\
2,6 \\
\end{array}$ & $9,7 \%$ \\
\hline Serra & $\begin{array}{c}24,1 \% \\
, 7 \\
\end{array}$ & $\begin{array}{c}18,8 \% \\
.2,5 \\
\end{array}$ & $\begin{array}{c}17,6 \% \\
.2,1\end{array}$ & $\begin{array}{c}28,4 \% \\
3,1 \\
\end{array}$ & $23,4 \%$ \\
\hline Garotinho & $\begin{array}{c}12,5 \% \\
\cdot, 5 \\
\end{array}$ & $\begin{array}{c}15,0 \% \\
1,4 \\
\end{array}$ & $\begin{array}{c}13,1 \% \\
, 1 \\
\end{array}$ & $\begin{array}{c}12,1 \% \\
\cdot, 7 \\
\end{array}$ & $13,0 \%$ \\
\hline Outro & $\begin{array}{c}1,2 \% \\
1,6 \\
\end{array}$ & $\begin{array}{c}1,4 \% \\
1,6 \\
\end{array}$ & $\begin{array}{l}, 0 \% \\
.1,4 \\
\end{array}$ & $\begin{array}{c}, 0 \% \\
.2,3 \\
\end{array}$ & ,8\% \\
\hline Total & $(862)$ & $(426)$ & $(221)$ & $(514)$ & $(2023)$ \\
\hline
\end{tabular}

\begin{tabular}{|c|c|c|c|c|c|}
\hline $\begin{array}{c}\text { Escolha Eleitoral 1 } \\
\text { Turno 2006 }\end{array}$ & Classe Baixa & Média-Baixa & Média-Média & Média-Alta & Total \\
\hline Lula & $77,0 \%$ & $62,8 \%$ & $56,5 \%$ & $38,1 \%$ & $67,8 \%$ \\
& 5,7 & $-1,8$ & $.3,0$ & $.4,2$ & \\
\hline Geraldo Alckmin & $17,4 \%$ & $25,6 \%$ & $29,8 \%$ & $47,6 \%$ & $23,3 \%$ \\
& $-4,0$ &, 9 & 1,9 & 3,8 & \\
\hline Heloísa Helena & $2,8 \%$ & $7,0 \%$ & $7,3 \%$ & $7,1 \%$ & $4,9 \%$ \\
& $-2,8$ & 1,7 & 1,4 &, 7 & \\
\hline Outros & $2,8 \%$ & $4,5 \%$ & $6,5 \%$ & $7,1 \%$ & $4,1 \%$ \\
& $-1,9$ &, 4 & 1,5 & 1,0 & \\
\hline
\end{tabular}

\begin{tabular}{|c|c|c|c|}
\hline Chi quadrado (pearson) & Valor & Grau de Liberdade & Significância \\
\hline Escolha eleitoral 1 Turno -2006 & $22,178(a)$ & 6 &, 001 \\
\hline Escolha eleitoral 1 Turno -2006 & $44,624(\mathrm{~b})$ & 9 &, 000 \\
\hline
\end{tabular}

b. 2 cells $(12,5 \%)$ have expected count less than 5 . The minimum expected count is 1,71 Fonte: ESEB, 2006

Os resultados da eleição de 2006 mostram um quadro bastante distinto. Nessa eleição, estratificação social aparece como uma variável muito mais relevante para a explicação dos padrões de distribuição do voto. Antes de mais nada, é 
possível constatar que nessa eleição há uma clara clivagem no eleitorado com relação à candidatura de Luiz Inácio Lula da Silva: enquanto os eleitores da classe baixa se mostram significativamente mais inclinados a dar seu voto a Lula, a adesão a essa candidatura cai entre os eleitores dos estratos médios, decrescendo sistematicamente à medida que se passa do estrato médio-baixo para o estrato médio-médio e deste para o estrato médio-alto. Em termos proporcionais, $77 \%$ dos eleitores da classe baixa declararam ter votado em Lula em 2006, com o resíduo ajustado indicando uma associação positiva forte e significativa entre esses eleitores e a candidatura Lula. Essa proporção cai para $63 \%$ entre os eleitores do estrato médio-baixo, para $56 \%$ entre os eleitores do estrato médio-médio e chega ao seu nível mais baixo entre os eleitores do estrato médio-alto: $38 \%$ dos votos desses eleitores. Por outro lado, Alckmin, que em 2006 representou a coligação que apoiou o governo anterior, de Fernando Henrique Cardoso, recebe significativamente menos votos entre os eleitores de baixa renda $(17 \%$, contra $23 \%$ na população) e conta com um apoio mais sólido entre os eleitores dos estratos médio-superior, no qual $48 \%$ dos eleitores declararam voto em sua candidatura.

Esses resultados apontam, portanto, para um reforço da dimensão da estratificação social para a definição dos resultados eleitorais na eleição de 2006, quando comparada à eleição de 2002. O Quadro 3 apresenta os resultados da regressão entre estratificação social e o voto na candidatura Lula nas eleições de 2002 e 2006.

Quadro 3 -Voto em Lula e Estratificação Social

\begin{tabular}{|c|c|c|c|c|}
\hline Ano & $\mathrm{R}$ & $\mathrm{R}^{2}$ & $\begin{array}{c}\mathrm{R}^{2} \\
\text { ajustado }\end{array}$ & $\begin{array}{c}\text { Desvio } \\
\text { Padrão }\end{array}$ \\
\hline Eleição 2002 &, $006(\mathrm{a})$ &, 000 &, 000 &, 49490 \\
Eleição 2006 &, $145(\mathrm{a})$ &, 021 &, 020 &, 49006 \\
\hline
\end{tabular}

a Preditor: (Constante), estratificaçao

Análise de Variância

\begin{tabular}{|c|c|c|c|c|c|c|}
\hline \multirow{2}{*}{ Ano } & & $\begin{array}{c}\text { Soma dos } \\
\text { quadrados }\end{array}$ & $\begin{array}{c}\text { Grau de } \\
\text { liberdade }\end{array}$ & $\begin{array}{c}\text { Quadrado da } \\
\text { média }\end{array}$ & $F$ & Sig. \\
\hline \multirow{2}{*}{2002} & Regressão &, 022 & 1 &, 022 &, 091 &, $762(a)$ \\
\cline { 2 - 7 } & Resíduos & 614,922 & 2511 &, 245 & & \\
\cline { 2 - 7 } & Total & 614,944 & 2512 & & & \\
\hline \multirow{2}{*}{2006} & Regressão & 4,674 & 1 & 4,674 & 19,464 &, $000(\mathrm{a})$ \\
\cline { 2 - 8 } & Resíduos & 216,142 & 900 &, 240 & & \\
\cline { 2 - 8 } & Total & 220,816 & 901 & & & \\
\hline
\end{tabular}

a preditor: (Constante), estratificação

b Variável dependente: Voto (Lula)

Fonte: ESEB, 2006 
BALBACHEVSKY, E.; HOLZHACKER, D. O. Classe, ideologia e política: uma interpretação...

Os resultados confirmam as conclusões obtidas a partir da análise da Tabela 1. De fato, enquanto em 2002 a estratificação social não teve peso significativo na explicação dos padrões de distribuição do voto em Lula, em 2006, essa variável aumenta em relevância: a associação positiva entre o voto nesse candidato e as camadas mais pobres e, simultaneamente, sua rejeição entre os eleitores dos estratos mais altos faz dessa variável uma dimensão relevante para a explicação dos padrões da distribuição dos votos no candidato petista em 2006. Enquanto em 2002 a variável socioeconômica não tinha associação com o voto em Lula (com $R^{2}$ $0,00)$, em 2006 cresce $20 \%\left(R^{2} 0,20\right)$ sua propriedade preditiva quanto ao voto em Lula. Esse resultado é relevante, apesar de estatisticamente pouco expressivo, pois indica o aumento do peso dessa variável entre 2002 e 2006. Assim sendo, corrobora a hipótese de que a estratificação eleitoral foi uma variável significativa na eleição presidencial de 2006.

Resta, portanto, avaliar quais conteúdos substantivos, em termos de valores e atitudes, estão também associados à decisão de voto em Lula nas duas eleições. Como assinalamos no início deste trabalho, duas correntes se confrontam na interpretação da votação de Lula nas eleições de 2006. A primeira delas vê nessa votação a expressão de um voto "classista", com fortes conotações ideológicas que, em sua interpretação mais extrema, opõe aqueles que, por anos, governaram o país e sustentaram políticas que contribuíram para o acirramento do quadro de desigualdade e da pobreza, contra a massa de desvalidos que se inclinou a favor do candidato operário que, no seu primeiro mandato, teve sucesso na implementação de políticas compensatórias visando corrigir as desigualdades históricas. Outra interpretação aponta para um relativo esvaziamento da dimensão ideológica da candidatura petista, substituída por um padrão de voto mais pragmático, que expressa a satisfação do eleitor com políticas que o beneficiam no seu dia-a-dia. Assim, os bons resultados da candidatura Lula junto aos eleitores de baixa renda, na disputa pelo seu segundo mandato, seriam explicados principalmente pelo sucesso das políticas de redistribuição de renda e que tinham como população alvo justamente os estratos de baixa renda da população.

Para estabelecer qual dessas duas hipóteses encontra sustentação nos dados coletados pela pesquisa ESEB em 2002 e 2006, procedemos a um exercício de análise multivariada, que permite derivar uma função da probabilidade de que um caso seja classificado em determinada categoria da variável dependente $(Y)$ em função de uma combinação linear de $X$ variáveis. Assim, o modelo estatístico que será estimado é o seguinte:

$$
\begin{aligned}
& \mathrm{L}_{\mathrm{n}} \mathrm{Y}=\mathrm{E}_{0}+\mathrm{E}_{1} X_{1}+\mathrm{E}_{2} X_{2}+\mathrm{E}_{3} X_{3}+\mathrm{E}_{4} X_{4}+\mathrm{E}_{5} X_{5}+\mathrm{E}_{6} X_{6}+\mathrm{E}_{7} X_{7}+\mathrm{E}_{8} X_{8}+\mathrm{E}_{9} X_{9}+ \\
& \mathrm{E}_{10} X_{10}+\mathrm{E}_{11} X_{11}+\mathrm{E}_{12} X_{12}+\mathrm{E}_{13} X_{13}+\mathrm{B}_{14} X_{14}
\end{aligned}
$$


Onde:

Y corresponde à probabilidade de voto em Lula, e

$\mathrm{E}_{0}$ é o valor cumulativo estimado dessa probabilidade quando todas as variáveis independentes assumem valor zero.

Na eleição de 2002, as variáveis independentes no modelo são:

$X_{1}=$ Ideologia, posição que o entrevistado se atribui numa escala de 1 a 10 , na qual 1 corresponde à posição mais à esquerda, e 10 corresponde à posição mais à direita.

$X_{2}=$ Avaliação do governo $\mathrm{FHC}$, na qual o entrevistado escolhe valores entre 1 e 5, correspondendo a uma avaliação entre péssima, ruim, regular, boa e ótima.

$X_{3}=$ Popularidade de Lula, expressa pelo grau em que o entrevistado expressa o quanto gosta ou não de Lula numa escala de 0 a 10 , na qual 0 corresponde a não gosta, e 10 corresponde a gosta muito.

$X_{4}=$ Principal problema, em que o entrevistado aponta quais seriam os principais problemas do país, agrupados em quatro temas: questões econômicas, questões relacionadas à desigualdade e pobreza; políticas públicas e sistema político/corrupção.

$X_{5}=$ Grau de satisfação com a democracia, em que os entrevistados indicaram o quanto se encontram "muito satisfeito", "satisfeito", "pouco satisfeito" e "nada satisfeito" com o funcionamento da democracia no Brasil.

Para a eleição de 2006, as variáveis dependentes mudam, adaptando-se tanto à realidade da candidatura de Lula à reeleição, como também às de diferenças no conteúdo do questionário aplicado. Assim, em 2006, as variáveis independentes do modelo são:

$X_{1}=$ Ideologia, posição que o entrevistado se atribui numa escala de 1 a 10 , na qual 1 corresponde à posição mais à esquerda, e 10 corresponde à posição mais à direita.

$X_{2}=$ Grau de satisfação com a democracia, em que o entrevistado indica se está "muito satisfeito", "satisfeito", "pouco satisfeito" e "nada satisfeito" com o funcionamento da democracia no Brasil.

$X_{3}=$ Avaliação do governo Lula, em que o entrevistado escolhe valores entre 1 e 5, correspondendo a uma avaliação péssima, ruim, regular, boa ou ótima.

$X_{4}=$ Principal problema, em que o entrevistado aponta quais seriam os principais problemas do país, agrupados em quatro temas: questões econômicas, questões corrupção e éticas, políticas públicas e sistema político.

$X_{5}=$ Popularidade de Lula, expressa pelo grau em que o entrevistado expressa o quanto gosta ou não de Lula numa escala de 0 a 10 , onde 0 corresponde a não gosta, e 10 corresponde a gosta muito. 
BALBACHEVSKY, E.; HOLZHACKER, D. O. Classe, ideologia e política: uma interpretação...

Os resultados desse exercício estão no Quadro 4:

Quadro 4: Regressão linear - aspectos explicativos do voto em Lula (2002/2006)

\section{Sumário}

\begin{tabular}{|c|c|c|c|c|}
\hline Model & $\mathrm{R}$ & $\mathrm{R}^{2}$ & $\begin{array}{c}\mathrm{R}^{2} \\
\text { ajustado }\end{array}$ & $\begin{array}{c}\text { Desvio } \\
\text { Padrão }\end{array}$ \\
\hline 2002 &, $420(\mathrm{a})$ &, 176 &, 170 &, 45548 \\
\hline 2006 &, $570(\mathrm{a})$ &, 325 &, 319 &, 40888 \\
\hline
\end{tabular}

2002 preditores: (Constant), Opinião sobre democracia, principal problema, ideologia, GostaLula, avaliacaoGovFHC

2006 preditores: (Constant), Gosta ou Não Lula, idelogia, principal_problema, satisfaçao com a democracia, avaliação do governo

ANOVA

\begin{tabular}{|cc|c|c|c|c|c|}
\cline { 3 - 7 } \multicolumn{1}{c|}{} & & $\begin{array}{c}\text { Soma dos } \\
\text { quadrados }\end{array}$ & $\begin{array}{c}\text { Grau de } \\
\text { liberdade }\end{array}$ & $\begin{array}{c}\text { Quadrado } \\
\text { das médias }\end{array}$ & $\mathrm{F}$ & Sig. \\
\hline 2002 & Regressão & 31,268 & 5 & 6,254 & 30,143 &, $000(\mathrm{a})$ \\
& Residuos & 146,216 & 705 &, 207 & & \\
& Total & 177,485 & 710 & & & \\
\hline 2006 & Regressão & 42,333 & 5 & 8,467 & 50,643 &, $000(\mathrm{a})$ \\
& Residuos & 87,769 & 525 &, 167 & & \\
& Total & 130,102 & 530 & & & \\
\hline
\end{tabular}

2002 Preditores: (Constante), Opinião sobre democracia, problema, ideologia, Gosta Lula, avaliação Gov FHC

2006 Preditores: (Constante), Gosta ou Não Lula, idelogia, principal_problema, satisfação democracia, avaliação do governo

b variável dependente: voto em Lula 
OPINIÃO PÚBLICA, Campinas, vol. 13, n², Novembro, 2007, p.283-306

\section{Coeficientes (a)}

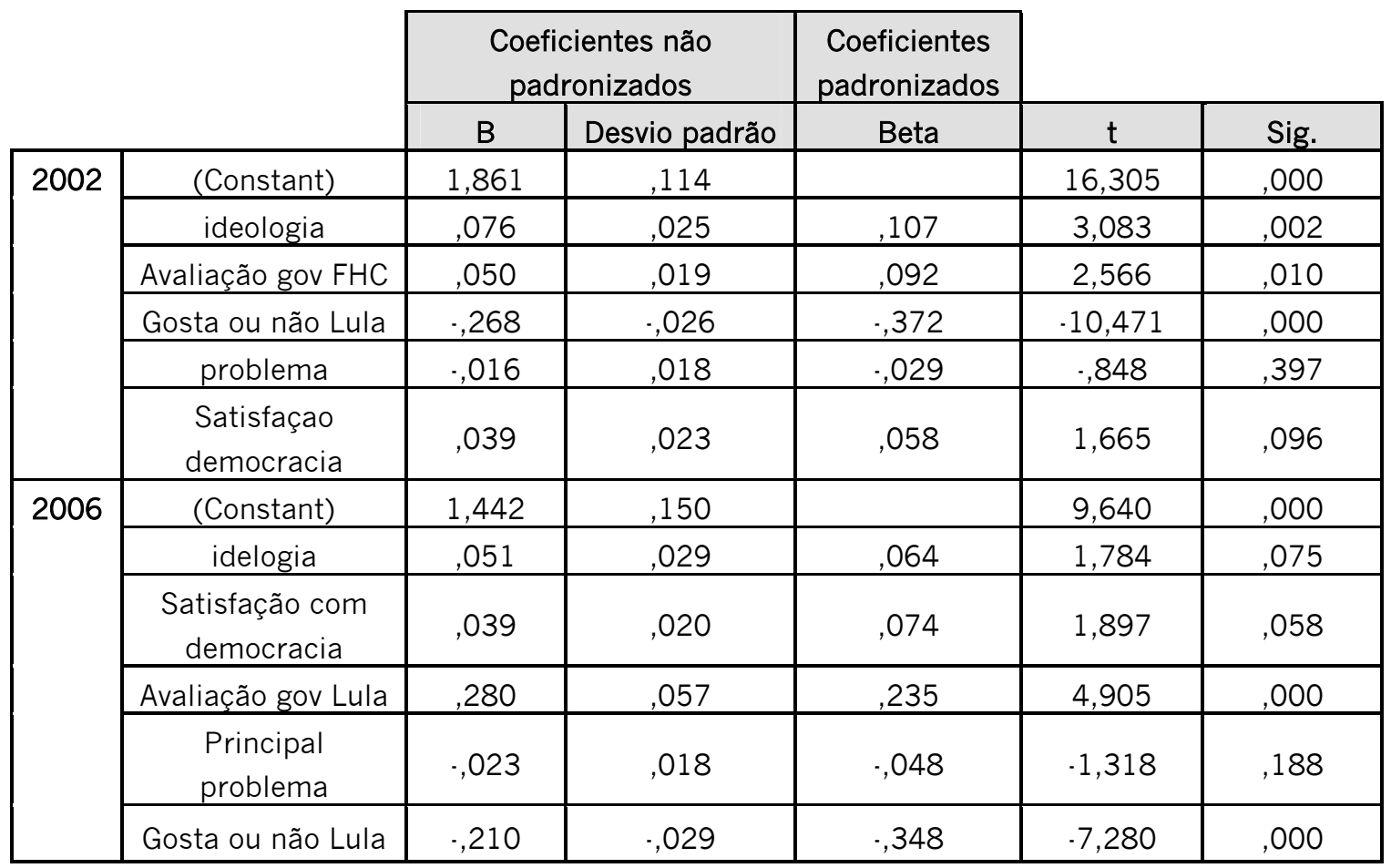

a. variável dependente: voto em Lula

A análise de regressão indica que há um aumento do impacto das variáveis independentes entre 2002 e 2006: enquanto em 2002 as variáveis independentes explicavam apenas $17,6 \%$ da variação do voto em Lula, em 2006 o modelo passa a explicar $31,9 \%$ da escolha eleitoral. É possível supor que alguns dos indicadores cresceram em importância passando a ter maior impacto na decisão do voto em Lula entre 2002 e 2006.

Esse quadro mostra que em 2002 as dimensões relevantes para entender o voto no candidato Lula foram o auto-posicionamento ideológico do eleitor, a avaliação do desempenho do governo de Fernando Henrique Cardoso, e a simpatia do eleitor com o candidato Lula. As demais variáveis utilizadas no modelo mostraram-se não-significativas para estimar a probabilidade de decisão de voto favorável a Lula (significância do coeficiente igual ou maior que 0,05). Em 2006, a mudança mais importante está justamente no fato de que a auto-identidade ideológica do eleitor perde completamente sua capacidade preditiva com relação à decisão de voto favorável a Lula. Na eleição de 2006, as únicas dimensões do modelo que permanecem com alguma capacidade preditiva são a avaliação 
BALBACHEVSKY, E.; HOLZHACKER, D. O. Classe, ideologia e política: uma interpretação...

favorável ao governo Lula e a identidade pessoal que o eleitor estabelece com esse candidato. A importância da dimensão da simpatia e identidade para a candidatura Lula é conhecida e permanece ao longo de todas as eleições em que esse candidato participou nas três últimas décadas (BALBACHEVSKY e HOLZHACKER, 2004). A análise de regressão apresentada indica que essa é a dimensão mais forte para explicar a decisão de voto favorável a Lula nas duas eleições consideradas.

É notável que a associação entre voto e a identidade com Lula mostra uma relação negativa, ou seja, quanto menor a identificação com o candidato Lula menor a possibilidade de escolhê-lo como candidato. Assim, essa associação indica que entre 2002 e 2006 houve uma pequena diminuição do grau de rejeição com relação ao candidato: enquanto em 2002 o coeficiente $\beta$ representava $-0,379$, em 2006, caiu para $-0,342$.

No modelo de regressão também foram incluídas duas variáveis que buscavam medir o impacto da dimensão conjuntural por meio, de um lado, da eleição do principal problema da agenda nacional e, por outro lado, da satisfação com o desempenho da democracia no Brasil nos últimos anos. Ambas as variáveis mostraram-se estatisticamente irrelevantes para predizer o voto no candidato, demonstrando que uma possível insatisfação com a democracia entre os eleitores e com a situação social e política no país não tiveram peso na definição do voto dos eleitores tanto em 2002 quanto em 2006. No caso da variável "satisfação com a democracia no Brasil", o coeficiente $\beta$ representava 0,058 em 2002 e passou para 0,74 em 2006, representando um aumento do peso desta variável dentro do modelo. Entretanto, em 2006, a associação dessa variável com o voto em Lula revela independência estatística (significância 0,096).

De outro lado, a associação entre avaliação do governo Lula e escolha do candidato indicou $23 \%$ de probabilidade de acerto comparada com as outras variáveis do modelo. Em 2002, a associação entre a avaliação do governo Fernando Henrique Cardoso e o voto em Lula tinha $9 \%$ de probabilidade de acerto dentro do modelo. Considerando que em 2006 o candidato Lula disputava o seu segundo mandato é possível supor quer os eleitores incluíram em seu cálculo eleitoral o desempenho do governo como fator importante para sua escolha. Por outro lado, o aumento relativo desta variável também corrobora a hipótese de que uma parcela considerável dos eleitores fez um cálculo pragmático sobre os benefícios da administração Lula.

A hipótese sobre o aumento do peso do voto pragmático fica mais evidente quando notamos a diminuição da dimensão ideológica na composição do voto no candidato Lula entre 2002 e 2006. O modelo de regressão indica diminuição da associação entre decisão eleitoral e auto-identificação ideológica, sendo que o coeficiente $\beta$ era 0,107 em 2002 caindo para 0,064 em 2006. Esses resultados 
para a dimensão do auto-posicionamento ideológico do eleitor são surpreendentes, dada a tradicional associação o voto em Lula e o eleitorado de esquerda.

A Tabela 3 apresenta o auto-posicionamento ideológico do eleitor e sua decisão de voto estratificada por faixas socioeconômicas e especifica os resultados agregados apresentados no Quadro 4:

Tabela 3 - Auto-posicionamento ideológico do eleitor e decisão eleitoral por estrato de renda.

\begin{tabular}{|c|c|c|c|c|c|}
\hline & & & & \multirow{3}{*}{$\begin{array}{c}\text { Direita } \\
75,9 \% \\
., 4 \\
\end{array}$} & \multirow[b]{3}{*}{$77,5 \%$} \\
\hline & \multirow{2}{*}{$\begin{array}{c}\text { Esquerda } \\
77,8 \% \\
, 0 \\
\end{array}$} & \multirow{2}{*}{$\begin{array}{c}\text { Centro } \\
78,5 \% \\
, 4 \\
\end{array}$} & & \\
\hline \multirow{4}{*}{ Baixa renda } & Lula & & & & \\
\hline & Alckmin & $\begin{array}{c}11,1 \% \\
., 8 \\
\end{array}$ & $\begin{array}{c}15,9 \% \\
-, 7 \\
\end{array}$ & $\begin{array}{c}21,5 \% \\
1,2 \\
\end{array}$ & $17,6 \%$ \\
\hline & Outros & $\begin{array}{c}11,1 \% \\
1,3\end{array}$ & $\begin{array}{c}5,6 \% \\
, 5\end{array}$ & $\begin{array}{c}2,5 \% \\
-1,2\end{array}$ & $4,9 \%$ \\
\hline & TOTAL & $(18)$ & $(107)$ & (79) & $(204)$ \\
\hline \multirow{4}{*}{$\begin{array}{c}\text { Classe } \\
\text { média Baixa }\end{array}$} & Lula & $\begin{array}{c}81,8 \% \\
1,4 \\
\end{array}$ & $\begin{array}{c}56,2 \% \\
-1,6 \\
\end{array}$ & $\begin{array}{c}67,5 \% \\
, 9 \\
\end{array}$ & $62,1 \%$ \\
\hline & Alckmin & $\begin{array}{c}18,2 \% \\
., 8 \\
\end{array}$ & $\begin{array}{c}32,9 \% \\
1,4\end{array}$ & $\begin{array}{c}22,5 \% \\
-1,0 \\
\end{array}$ & $28,2 \%$ \\
\hline & Outros & $\begin{array}{l}, 0 \% \\
-1,1 \\
\end{array}$ & $\begin{array}{c}11,0 \% \\
, 6 \\
\end{array}$ & $\begin{array}{c}10,0 \% \\
, 1 \\
\end{array}$ & $9,7 \%$ \\
\hline & TOTAL & (11) & (73) & $(40)$ & $(124)$ \\
\hline \multirow{4}{*}{$\begin{array}{l}\text { Classe } \\
\text { média } \\
\text { média }\end{array}$} & Lula & $\begin{array}{c}60,0 \% \\
, 1 \\
\end{array}$ & $\begin{array}{c}68,2 \% \\
2,0 \\
\end{array}$ & $\begin{array}{c}40,0 \% \\
-2,2 \\
\end{array}$ & $58,2 \%$ \\
\hline & Alckmin & $\begin{array}{c}20,0 \% \\
., 7 \\
\end{array}$ & $\begin{array}{c}20,5 \% \\
-1,9 \\
\end{array}$ & $\begin{array}{c}48,0 \% \\
2,5 \\
\end{array}$ & $29,1 \%$ \\
\hline & Outros & $\begin{array}{c}20,0 \% \\
, 7 \\
\end{array}$ & $\begin{array}{c}11,4 \% \\
., 4 \\
\end{array}$ & $\begin{array}{c}12,0 \% \\
-, 1 \\
\end{array}$ & $12,7 \%$ \\
\hline & TOTAL & $(10)$ & $(44)$ & $(25)$ & (79) \\
\hline \multirow{4}{*}{$\begin{array}{c}\text { Classe } \\
\text { média alta }\end{array}$} & Lula & $\begin{array}{c}66,7 \% \\
1,1 \\
\end{array}$ & $\begin{array}{c}38,9 \% \\
, 1 \\
\end{array}$ & $\begin{array}{c}25,0 \% \\
., 9 \\
\end{array}$ & $37,9 \%$ \\
\hline & Alckmin & $\begin{array}{c}33,3 \% \\
., 4\end{array}$ & $\begin{array}{c}38,9 \% \\
., 8 \\
\end{array}$ & $\begin{array}{c}62,5 \% \\
1,2 \\
\end{array}$ & $44,8 \%$ \\
\hline & Outros & $\begin{array}{c}, 0 \% \\
-, 8 \\
\end{array}$ & $\begin{array}{c}22,2 \% \\
, 9 \\
\end{array}$ & $\begin{array}{c}12,5 \% \\
-, 4 \\
\end{array}$ & $17,2 \%$ \\
\hline & TOTAL & (3) & $(18)$ & $(8)$ & $(29)$ \\
\hline
\end{tabular}


BALBACHEVSKY, E.; HOLZHACKER, D. O. Classe, ideologia e política: uma interpretação...

\begin{tabular}{|c|c|c|c|c|}
\hline Estrato social & estatística & valor & $\begin{array}{c}\text { Grau de } \\
\text { Liberdade }\end{array}$ & significância \\
\hline \multirow[t]{2}{*}{ Baixa renda } & $\begin{array}{c}\text { Chi-quadrado } \\
\text { (Pearson) }\end{array}$ & $3,763(a)$ & 4 & ,439 \\
\hline & $\mathrm{N}$ de casos válidos & 204 & & \\
\hline \multirow[t]{2}{*}{ Classe média baixa } & $\begin{array}{l}\text { Chi-quadrado } \\
\text { (Pearson) }\end{array}$ & $3,901(b)$ & 4 & ,420 \\
\hline & $\mathrm{N}$ de casos válidos & 124 & & \\
\hline \multirow[t]{2}{*}{ Classe média média } & $\begin{array}{c}\text { Chi-quadrado } \\
\text { (Pearson) }\end{array}$ & 7,155 (c) & 4 & , 128 \\
\hline & $\mathrm{N}$ de casos válidos & 79 & & \\
\hline \multirow[t]{2}{*}{ Classe média alta } & $\begin{array}{l}\text { Chi-quadrado } \\
\text { (Pearson) }\end{array}$ & $2,678(d)$ & 4 &, 613 \\
\hline & $\mathrm{N}$ de casos válidos & 29 & & \\
\hline
\end{tabular}

Fonte: ESEB, 2006.

Como é possível verificar nessa Tabela, os testes estatísticos de significância para cada estrato social mostram que, nas eleições de 2006, ideologia e decisão de voto não estiveram associadas com qualquer dos estratos sociais considerados.

\section{Conclusões}

Os resultados que alcançamos com as análises apresentadas neste artigo mostram uma evolução surpreendente do eleitorado entre as eleições de 2002 e 2006. De um lado, constatamos que a estratificação social foi pouco relevante para explicar a decisão eleitoral nas eleições de 2002. Mais ainda, quando consideramos a decisão de votar ou não no candidato que polarizou aquelas eleições, Lula, esta não foi afetada pelo pertencimento do eleitor a diferentes estratos sociais. Entretanto, naquela eleição, a decisão de voto em Lula foi significativamente influenciada pela auto-identidade ideológica do eleitor. Eleitores que se posicionavam à esquerda tinham maior probabilidade de votar em Lula.

Nas eleições de 2006, ao contrário, a estratificação social revelou-se uma variável importante para a predição do voto do eleitorado brasileiro. Mas, surpreendentemente, nessas eleições, a dimensão ideológica perdeu força preditiva em relação ao voto. Em todos os estratos sociais que consideramos em nossa análise, o posicionamento ideológico dos eleitores foi pouco importante para explicar a decisão do voto. Como assinalamos anteriormete, esse resultado é tanto mais surpreendente quando se considera a forte e tradicional associação entre o voto em Lula e a auto-identidade de esquerda do país. Por outro lado, ele tende a corroborar a interpretação mais cética, que 
vê um esvaziamento da dimensão ideológica e do confronto de classes para explicar a vitória de Lula nas eleições de 2006. Quaisquer que tenham sido as outras motivações do eleitorado que votou em Lula, as questões ideológicas que tradicionalmente motivaram seus eleitores estiveram ausentes nesta eleição.

Do ponto de vista teórico, os resultados dessa análise são bastante relevantes já que, tanto nas eleições de 2002 como nas eleições de 2006, as duas variáveis que constituem o centro da análise deste artigo, estratificação social e identidade ideológica, mostraram um comportamento independente uma da outra. Assim, novas análises são necessárias para, de um lado, compreender os conteúdos ideacionais que se associam a diferentes posições de auto-identidade ideológica; de outro lado, estes resultados criam a necessidade de investigar mais a fundo a natureza das opiniões, atitudes e expectativas que estiveram associadas ao voto em Lula em 2006.

\section{Referências bibliográficas}

AMARAL, R. "As eleições de 2006 e a emergência das grandes massas no processo político". Comunicação\&política, v.24, n³, p.007-017, 2006. Disponível em:

<http://www.cebela.org.br/imagens/Materia/0-0320Editorial.pdf >. Acesso em: jul. 2007.

BALBACHEVSKY, E. e HOLZHACKER, D. O. "Identidade, oposição e pragmatismo: o conteúdo estratégico da decisão eleitoral em 13 anos de eleições". Opinião Pública. Campinas:

CESOP/UNICAMP, vol. X, no.2, p.242 - 253, 2004.

BERGAMO, M. "Entrevista Luiz Inácio Lula da Silva: Lula se diz frustrado por falta de apoio entre os mais ricos". Folha de São Paulo, 18 set. 2006.

BOSCHI, R. "A abertura e a Nova Classe Média na Política Brasileira: 1977.82". Dados, vol.29, $n^{\circ} .1$, p. 5-24, 1986.

BRESSER-PEREIRA, L.C. "The Rise of Middle Class and Middle Management in Brazil" Journal of Inter-American Studies, vol.4, nº.3, p.313-326, 1962.

"A classe média". Folha de S.Paulo, 13.dez. 2006. Disponível em:

<http://www.bresserpereira.org.br/ver file.asp?id=2177>. Acesso em: jul. 2007. 
BALBACHEVSKY, E.; HOLZHACKER, D. O. Classe, ideologia e política: uma interpretação...

BURRIS, V. "The Discorvery of the New Middle Class". Theory and Society, vol.15, p.317-349, 1986.

CARREIRÃO, Y. S. "Relevant factors for the voting decision in the 2002 presidential election: an analysis of the ESEB (Brazilian Electoral Study) Data". Brazilian Political Science Review, vol.1, p.70-101. Disponível em:

<http://www.bpsr.org.br/english/arquivos/bpsr v1 n1 march2007.pdf>. Acesso em: jul. 2007.

FIGUEIREDO, A. "Fora do jogo: a experiência dos negros na classe média brasileira". Cadernos Pagu. Campinas: PAGU/UNICAMP, n॰. 23, p. 199-228, 2004.

FUNDAÇÃO PERSEU ABRAMO. "A classe média nas eleições de 2006”. Boletim Periscópio. Edição 57, mai. 2006. Disponível em: <http://www.perseuabramo.org.br>

GERTEIS, J. "Political Alignment and the American Middle Class, 1974-1994". Sociological Forum, vol. 13, n॰4, p. 639.666, 1998.

GUERRA, A. et al (orgs.). A classe média: desenvolvimento e crise. São Paulo: Editora Cortez, 2006.

KRISCHKE, P. "Governo Lula: Políticas de reconhecimento e de redistribuição". Cadernos de Política Interdisciplinar em Ciências Humanas - PPGIH, n॰47. Out. 2003. Disponível em: $<$ http://www.cfh.ufsc.br/ dich/TextoCaderno47.pdf >. Acesso em: jul. 2007.

MATTAR, F. N. "Análise crítica dos estudos de estratificação sócio-econômica de ABA-Abipeme". Revista de Administração, vol.30, n॰1, p. 57.74, jan/mar. 1995. Disponível em: <http://www.fauze.com.br/artigo10.htm>

MEZAN, R. "O mapa complexo das urnas". Folha de São Paulo. Caderno Mais. 15 out. 2006.

MILLS, W. White Collor: the american middle classes. New York: Oxford University Press, 1953.

NICOLAU, J. "An Analysis of the 2002 Presidential Elections Using Logistic Regression”. Brazilian Political Science Review, vol. 1, p.125-134. Disponível em: <http://www.bpsr.org.br/english/arquivos/bpsr v1 n1 march2007.pdf>. Acesso em: jul.2007.

O'DOUGHERTY, M. Consumption Intensified: the politics of middle-class daily life in Brazil. London: Duke University Press, 2002.

OLIVEIRA, F. Medusa ou as Classes Médias e a Consolidação democrática. In: REIS, F. W. e 
O'DONNEL, G. A democracia no Brasil: dilemas e perspectivas. São Paulo: Vértice, p. 210-231, 1988.

OWENSBY, B. P. Intimates Ironies: modernity and the making of the middle class lives in Brazil. Stanford: Stanford University Press, 1999.

PERLMUTTER, A. "The Myth of the Myth of the new Middle Class". Critical Studies in Society and History, vol.12, $\mathrm{n}^{\circ} .1, \mathrm{p} .14-26,1970$.

PORTES, A. "Latin America Class Structure: Their Composition and Change during the Last Decades". Latin American Research Review, vol.20, n.3, p.7-39, 1985.

QUADROS, W. "O encolhimento da classe média brasileira". Cesit - Carta Social e Trabalho, n॰5, abr.set.2006, p. 5-12. Disponível em:

<http://www.eco.unicamp.br/cesit/boletim/Versao Integral5.pdf>. Acesso em: jul.2007.

QUADROS, W. e ANTUNES, D. "Classes sociais e distribuição de renda no Brasil dos anos noventa". Cadernos do CESIT n॰30, out.2001. Disponível em:

<http://www.eco.unicamp.br/cesit/download cesit/cadernodoCESIT30.pdf>. Acesso em: jul.2007.

RATTERN, H. "O Declínio da classe média”. Revista espaço acadêmico, n॰57, jan.2006. Disponível em: <http://www.espacoacademico.com.br/057/57rattner.htm>. Acesso em jul.2007.

ROMANELLI, G. Famílias de camadas médias: a trajetória da modernidade. Tese de Doutorado, USP, São Paulo, 1986.

SANTOS, J. A. F. "Mudanças na estrutura de posições e segmentos de classe no Brasil". Revista Dados, vol. 44, n॰1. p. 97-153, 2001.

. "Uma classificação socioeconômica para o Brasil". Revista Brasileira de Ciências Sociais, vol. 20, n॰.58, p. 27.45, 2005.

SINGER, A. A Esquerda e direita no eleitorado brasileiro. São Paulo: EDUSP, 2000.

SINGER, P. "O PT e as eleições de 2006". Folha de São Paulo, Tendências e Debates, 05 out.2006.

VEJA. "Os desejos da classe média". Edição 1739, 20 fev.2002. Disponível em: <http://veja.abril.com.br/200202/p 098.html>. Acesso em: jul.2007. 